NBER WORKING PAPER SERIES

THE ESTIMATION OF LABOR SUPPLY

OVER KINKED BUDGET CONSTRAINTS:

SOME NEW ECONOMETRIC METHODOLOGY

Anthony J. Pellechio

Working Paper No. 387

NATIONAL BUREAU OF ECONOMIC RESEARCH

1050 Massachusetts Avenue

Cambridge MA 02138

August 1979

The research reported here is part of the NBER's research program in Social Insurance. Any opinions expressed are those of the author and not those of the National Bureau of Economic Research. There is an enormous debt to Gary Chamberlain throughout this study. Shortcomings are ray own. 


\section{"The Estimation of Labor Supply Over Kinked Budget Constraints: Some New Econometric Methodology"}

ABSTRACT

Most programs of taxation and income maintenance imply that the tax rate faced by an individual changes at different levels of labor supply. As a result, the individual's budget constraint is kinked which presents problems for the empirical study of labor supply. This paper developes econometric methodology for estimating labor supply in the presence of taxes. Equations for market wage and shadow price are used to describe labor supply choices over a kinked budget constraint. This approach makes a distinction between the discrete choice of which segment or corner of the kinked constraint to work on and the selection of the actual number of hours of work along linear segments. A consistent procedure is derived that uses all the tax rates faced by the individual and relies on no more structure than has been used in the previous literature on labor force participation. This procedure summarizes the individual's kinked budget constraint by calculating the expected value of variables that assume different values on the sections of the constraint. Techniques for estimating the model based on a probit analysis of the decision to work above or below certain corners of the budget constraint are presented. Maximum 1ikelihood estimation is also discussed.

Anthony J. Pellechio

Research Associate National Bureau of Economic Research 1050 Massachusetts Avenue Cambridge, MA 02140

$617 / 868-3919$ 
The purpose of this study is to develop econometric methodology for estimating labor supply in the presence of taxes. Government programs of income maintenance and taxation imply that the net wage faced by an individual changes at different levels of labor supply. Consequently, to the extent that an individual chooses his labor supply, he also chooses his tax rate. This selection of taxes by the individual presents problems for empirical tax analysis. It is incorrect to use the selected tax rate as an explanatory variable for measuring tax effects in a labor supply model. This specification is subject to simultaneity bias because labor supply and the tax rate are jointly determined. The problem is that labor supply is a function of all the tax rates faced by the individual. Although some progress has been made in implementing such a function empirically, it has been made by bringing a considerable amount of structure into the model. 1

This study developes a consistent method for estimating labor supply that uses all the tax rates faced by an individual and relies on no more structure than has been used in the previous literature on the subject: Other methods of estimation are presented as steps in this development. These methods constitute an empirical examination of labor supply in which it is possible to test whether individuals respond to taxes and achieve an equilibrium. It is alșo possible to examine whether models based on strong assumptions and a considerable amount of structure are justified. Such an examination is an.important part of empirical tax analysis.

This study is based on the realization of a connection between two different areas of research on labor supply. One area has to do with tax analysis and the other with sample selection. The first is best represented in a study by Rosen (1976) which examined the effect of income taxes on the labor supply of married woemn. The budget constraint of these women is kinked because their 
net wage makes abrupt changes as they move into different tax brackets. Rosen summarized the kinked budget constraint by computing the effect of taxes on earnings at a standard number of hours of work. Essentially the constraint was sumnarized by the average tax rate at a point, Other studies ${ }^{2}$ of labor supply and taxes have taken similar approaches by focusing on different points or constructing linear approximations of the budget constraint. These studies did not represent the entire budget constraint in any detail. Nonetheless, Rosen does remark that "ideally we want to represent the whole opportunity locus" and this task is taken up here.

Another group of labor supply studies ${ }^{3}$ that is not concerned about taxes focuses on decisions made at a particular corner of the budget constraint. The choice of whether or not to work - the participation decision - is used in these studies to analyze issues of bias in wage comparisons and sample selection. The analysis takes place at the corner of the budget constraint where hours of work equal zero. The comparison of market wage and reservation wage at this corner has important implications for the estimation of wages and labor supply: This analysis is extended in this study by carrying out the same comparison at other corners along the taxed budget corstraint in order to develop methods for estimating labor supply in the presence of taxes. Thus, the analysis of sample selection is used to address the tax selection problem discussed in the first paragraph. Also, it is the basis for finding a way "to represent the whole opportunity locus" as Rosen suggested.

Section II sets up a two-equation model of labor supply that serves as the foundation for the methodology developed in this study. This section presents techniques for estimating the model based on a probit analysis of the decision to work above or below certain corners of the budget constraint. This section also 
spells out under what condition these techniques can be applied to a nonconvex budget constraint. While showing that the model can be estimated by looking at discrete choices, the probit results are also needed ir. the methodology developed later on.

Section III brings hours of work into the estimation of the model and develops a consistent procedure for kinked budget constraints using ordinary least squares. The procedure summarizes the budget constraint in an intuitively appealing way by calculating the expected value of variables that assume different values on the sections of the constraint. The weights in this expected value equal the probabilities of choosing to work on these sections; the problt results of Section II are used to compute these probabilities. Because these probabilities depend on the parameters of the tax progran, it is possible to simulate behavioral responses to tax changes. Maximum likelihood estimation follows naturally from the consistent procedure and is presented in Section IV. Likelihood maximization can be used to examine the source of information in model estimates. Section $V$ discusses the problem posed by the nonconvex budget constraint for the consistent and maximum likelihood methods and proposes adjustments for each. The methodology presented here describes a process of defining a labor supply model for empirical study that brings in as much structure as is justified by the data. A summary and conclusion are given in section VI.

\section{A Two-Equation Mode1 of Labor Supp1y and Its Estimation Based on} Probit Analysis

A person decides to work based on the value of his time in market and nonmarket activities. In the market, his time is valued at his market wage. Outside the market the price that an individual attaches to his time is his shadow 
price. A person's shadow price when he does not work is defined to be his reservation wage. By definition, the reservation wage of a nonworker exceeds his market wage. When a person's reservation wage is less than his wage, he will work, i.e., he supplies labor in the market at his wage rate. As he increases his labor supply, a rise in his shadow price is predicted on the usual assumption that leisure is a normal good. A person supplies labor to the point where his shadow price equals his market wage. However, in the presence of income taxes or other income related programs, labor supply is no longer determined by equating shadow price and market wage. The process by which a labor supply equilibrium is achieved underlies the methods for estimating labor supply that are developed in this study. The discussion turns to a formal description of this process. The traditional analysis of labor force participation ${ }^{4}$ is the foundation of the methodology for eștimating labor supply developed here. The analysis uses equations to estimate an individual's market wage and shadow price. A person's potential wage, $w$; is related to a set of variables, $x$, and an error term $e_{1}$. This relationship is specified in the following semi-logarithmic form ${ }^{5}$ :

$$
\ln w=x_{\alpha}+e_{1}
$$

The $X$ variables consist of schooling and age as well as other determinants of wage. The error term, $e_{1}$, is assumed to be random and uncorrelated with the $X^{\prime} s$. The decision to work also depends on an individual's shadow price, denoted s. This is influenced by: time spent working, $h$; a set of observed variables, $Y$; and an error term, $e_{2}$. The general form of the shadow price equation is adopted from the wage equation as follows: 


$$
\ln s=Y \beta+\lambda h+e_{2}
$$

The $Y$ vector includes schooling and age, as does $X$, and other variables that influence shadow price alone. Labor supply is assumed to have a single time dimension measured by the scalar variable $h .{ }^{6}$ The error term is a random variable distributed independently. of $h$ and $Y$ by assumption:

A person will work when his reservation wage, i.e., $s$ at $h=0$, is less than his wage. Using eqs. (1) and (2) this means:

$$
e_{2}-e_{1}<X_{\alpha}-Y_{\beta}
$$

Let $D P$ be a binary variable that indicates whether a person works $(D P=1)$ or is not working $(D P=0)$. The probability of working, $P(D P=1)$, equals the probability that eq. (3) holds. Letting F denote the distribution function of $e_{2}-e_{1}$ and $\sigma$ denote the standard deviation of $e_{2}-e_{1}$, the probability of working becomes:

$$
P(D P=1)=F\left[\left(X_{\alpha}-Y \beta\right) / \sigma\right]
$$

The argument of $\mathrm{F}$ will be called the "participation index" because it determines labor force participation; it is denoted $\mathrm{J}_{0}$. 
The discussion turns to an analysis of labor force participation because it illustrates some points of technique that will be used again. The participation decision is the natural starting point for estimating labor supply. Estimates of $\alpha$ and $\beta$ up to the scale factor $\sigma$ are obtained from a participation analysis. This is done by dividing the sample into subsamples of individuals who are working, $\mathrm{DP}=1$, and those who are not working, $\mathrm{DP}=0$, and then maximizing the likelihood of observing this behavior in the sample. The likelihood function following from eq. (4) to be maximized is:

$$
L=\prod_{i \varepsilon\{D P=1\}}^{\pi} F\left(J_{O_{i}}\right) \underset{i \varepsilon\{D P=0\}}{\pi\left[1-F\left(J_{O_{i}}\right)\right.}
$$

where $J_{0_{i}}=$ the value of the participation index based on individual $i$ 's values for the variables. Maximum likelihood estimates of $\alpha / \sigma$ and $\beta / \sigma$ follow from the maximization of $L$. If a variable appears in both $X$ and $Y$, then only the difference between its coefficients in equations (1) and (2) relative to $\sigma$ can be identified.

When $F$ is the normal distribution function then eq. (5) is the standard probit model. Although the analysis is amenable to whatever distribution function is assumed for $F$, the probit specification is adopted because this has been the choice in the labor force participation literature.

A two-step procedure permits estimating all coefficients separately without any scale factor. In the first step, an estimate of $\alpha$ is obtained directly by estimating the wage equation alone. These results are used to impute the $\log$ of an individual's market wage based on $x$. In the second step, this imputed log of wage is used in a probit analysis of participation. The inverse of the estimated 
coefficient on the imputed $\log$ of wage is an estimate of the standard deviation in the denominator of the participation index. Multiplying the coefficient estimates for $Y$ variables by this estimate of the standard deviation yields maximum likelihood estimates of the $\beta^{\prime} s$.

This two-step procedure will be described explicitly: The first step produces an estimate of eq. (1) which is given as follows ${ }^{7}$ :

$$
\ln w=x \hat{\alpha}+\hat{e}_{1}=\ln \hat{w}+\hat{e}_{1} \text {. }
$$

The decision to work now implies:

$$
\mathrm{e}_{2}-\hat{\mathrm{e}}_{1}<\ln \hat{w}-\mathrm{Y}_{\beta} .
$$

Let $\mathrm{e}^{\prime}$ equal $\mathrm{e}_{2}-\hat{\mathrm{e}}_{1}$ and have standard deviation $\sigma^{\prime}$. The probability of working becomes:

$$
P(D P=1)=F\left[\left(\ln { }^{n} W-Y \beta\right) / \sigma^{\prime}\right]
$$

Let $J_{0}^{\prime}$ denote the argument of $\mathrm{F}$; the likelihood function based on eq. (8) is ${ }^{8}$ :

$$
L=\prod_{i \in\{D P=1\}} \Gamma\left(J^{\prime}{ }_{\theta_{i}}\right) \cdot \underset{i \in\{D P=0\}}{\pi\left[1-\Gamma\left(J{ }^{\prime}\right]\right.}
$$


This is the same as eq. (5) except that $1 \mathrm{n} \hat{w}$, the imputed $\log$ of wage, replaces Xand $\sigma^{\prime}$ replaces $\sigma$.

An important feature of the two-step procedure is that a single wage effect on participation is conveniently sumarized by the coefficient estimate of $\ln \hat{w}$. An estimate of $\sigma^{\prime}$ is given by the inverse of the estimated coefficient of $\ln ^{\hat{w}} \mathrm{w}$. An estimate of $B$ is obtained by multiplying the estimated coefficients of the $Y$ variables by the estimte of $\sigma^{\prime} .9$

It is possible to estimate $\beta$ using the probit analysis based on $X$ and $Y$ (eq. (5)) and the wage regression without carrying out the second probit step. Doing this requires that a variable be in but not in $Y$; let $x$, denote such a variable. The wage regression provides an estimate of $x_{1}$ 's coefficient in eq. (1) $-\hat{\alpha}_{1}$. The probit analysis yields an estimate of $x_{1}$ 's coefficient in the participation index $-\left(\alpha_{1} / \sigma\right)$. Thus, an estimate of $\sigma$ is given by $\hat{\alpha}_{1} /\left(\alpha_{1} / \sigma\right)$. If there are two (or more) variables in $X$ but not in $Y$, there would be two (or more) such estimates and $\sigma$ would be overidentified. A solution to this problem of overidentification is embedded in the two-step procedure. The inverse of coefficient estimate of $\ln \hat{w}$ in this procedure can be interpreted as a weighted average of the estimates of $\sigma$ in the overidentified case. ${ }^{10}$

Once a person has decided to work, the decision on how much labor to supply over a kinked budget constraint follows from a comparison of market wage and shadow price at points other than the corner of zero hours. The details of this approach are presented using the budget constraint illustrated in Figure 1. As shown, earnings are untaxed up to the level $M$ at which point a tax rate of $t$ is applied to further earnings. Hours of work at this kink point will be denoted by $k$. Thus, a person earns his full wage, $w$, for hours worked up to $k$ and earns his taxed wage, $(1-t) w$, for hours worked above $k$. 
Figure 1

THE CONVEX KINKED BUDGET CONSTRAINT

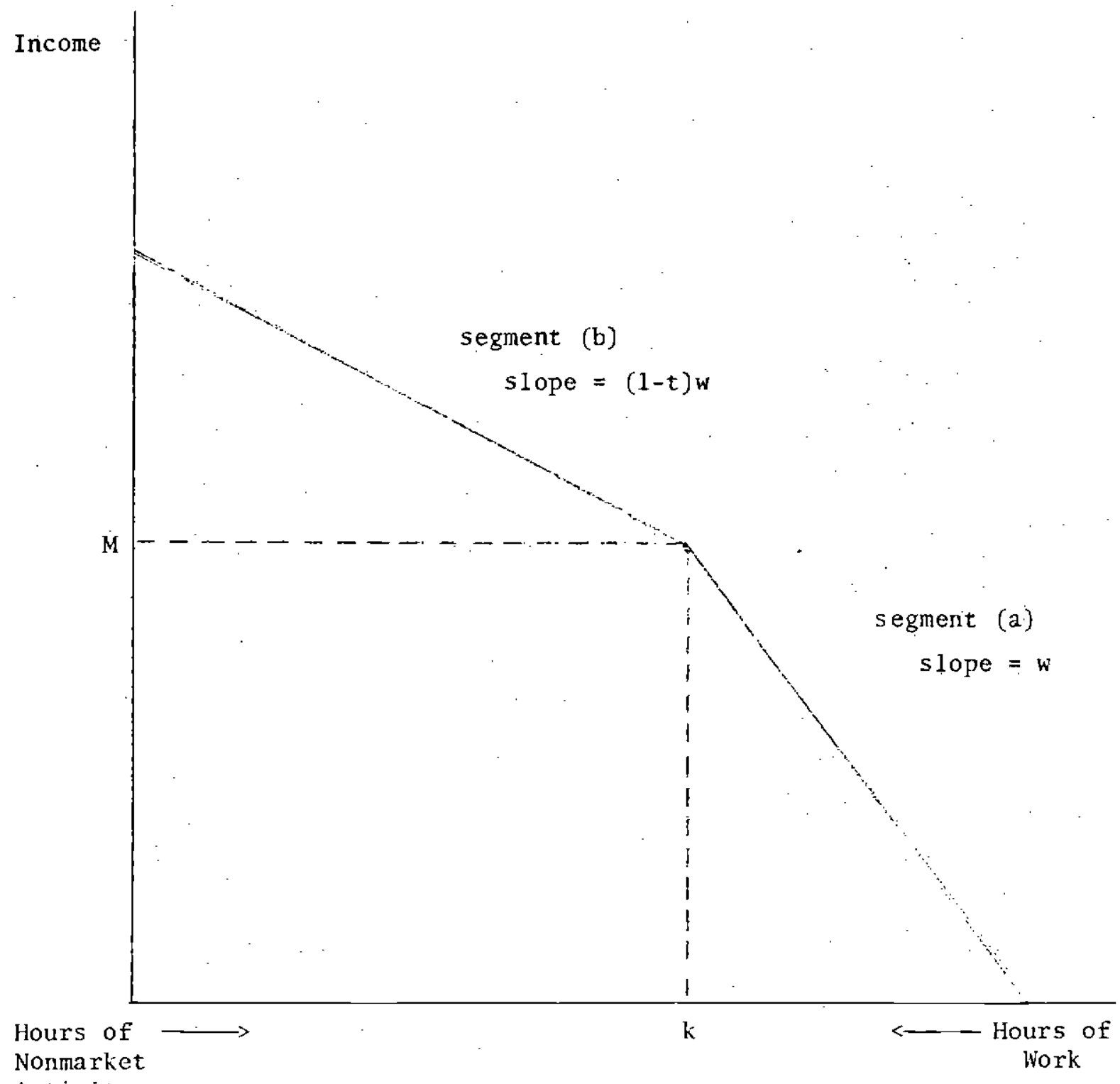

Activity 
A person works when $e_{2}-e_{1}<X_{\alpha}-Y_{B}$ but the amount of labor supplied depends on other wage and shadow price comparisons. Working below $\mathrm{k}$ implies that the shadow price of time at $k$ exceeds the market wage so that:

$$
\mathrm{e}_{2}-\mathrm{e}_{1}>\mathrm{X} \alpha-\mathrm{Y}_{\beta}-\gamma \mathrm{k}
$$

Using the same notation to describe the distribution of $e_{2}-e_{1}$ as before, the probability that a person works less than $k$ hours is given by:

$$
P(h<k)=1-F[(X \dot{\alpha}-Y \beta-\gamma k) / \sigma]
$$

The argument of F will be called the "index for working up $k^{\prime \prime}$ and is denoted $J_{k}$. The participation analysis described above did not yield an estimate of $\gamma$ because the analysis was applied where $h=0$. However, it is possible to estimate $\gamma$ along with the other parameters by applying probit analysis at the kink point. A binary vaiiable DK is used to indicate. whether a person works less than $k(D K=0)$ or at least $k$ hours $(D K=1)$. The sample is divided into the two subsamples corresponding to this classification and the likelihood function for observing this behavior is given by:

$$
L=\prod_{i \in\{D K=1\}} F\left(J_{k_{i}}\right) \cdot \prod_{i \varepsilon\{D K=0\}}\left[1-F\left(J_{k_{i}}\right)\right]
$$


where $J_{k_{i}}=$ the value of the index for working up to $k$ based on individual i's values for the variables. Maximun likelihood estimates of $\alpha / \sigma, \beta / \sigma$ and now $\gamma / \sigma$ are obtained by maximizing $\mathrm{L}$ with respect to these parameters. The same problem in estimating the separate coefficients of variables in both $X$ and $Y$ arises as it did before. The same two-step procedure can be applied as before in order to estimate $\alpha, \beta$ and $\gamma$ separately.

The probit analysis at the corner of zero hours and at the kink point may yield different estimates of the same coefficient and as a result provide a richer description of labor supply. For example, children can have opposite effects on the labor supply of women at these points. ${ }^{11}$ The presence of young children is expected to lower the probability of working. However, having decided to work, a woman's labor might be increased by the presence of children. in order to cover the cost of childcare. In other words, children become a fixed cost in labor supply decisions. Consequently, the coefficient of a variable measuring the effect of children can have a different sign in estimates of the model at zero hours and the kink point. The probit methods described above provide a direct examination of whether labor supply is influenced by fixed costs or other factors.

Although the above methods for estimating the models using probit analysis were constructed based on a convex budget, they can also be applied when the budget constraint is nonconvex subject to a certain condition. This condition is best illustrated with the aid of Figure 2. Three kinked nonconvex budget constraints, $A B C D_{1}, A B C D_{2}$ and $A B C D_{3}$, are shown in this figure. The extension of the common initial segment of all of these constraints is given by the dashed line BE. The probit methods for estimating the model presented in this section are valid on the condition that BE lies above the rest of the constraint. This condition 
Figure 2

NONCONVEX KINKED BUDGET CONSTRAINTS

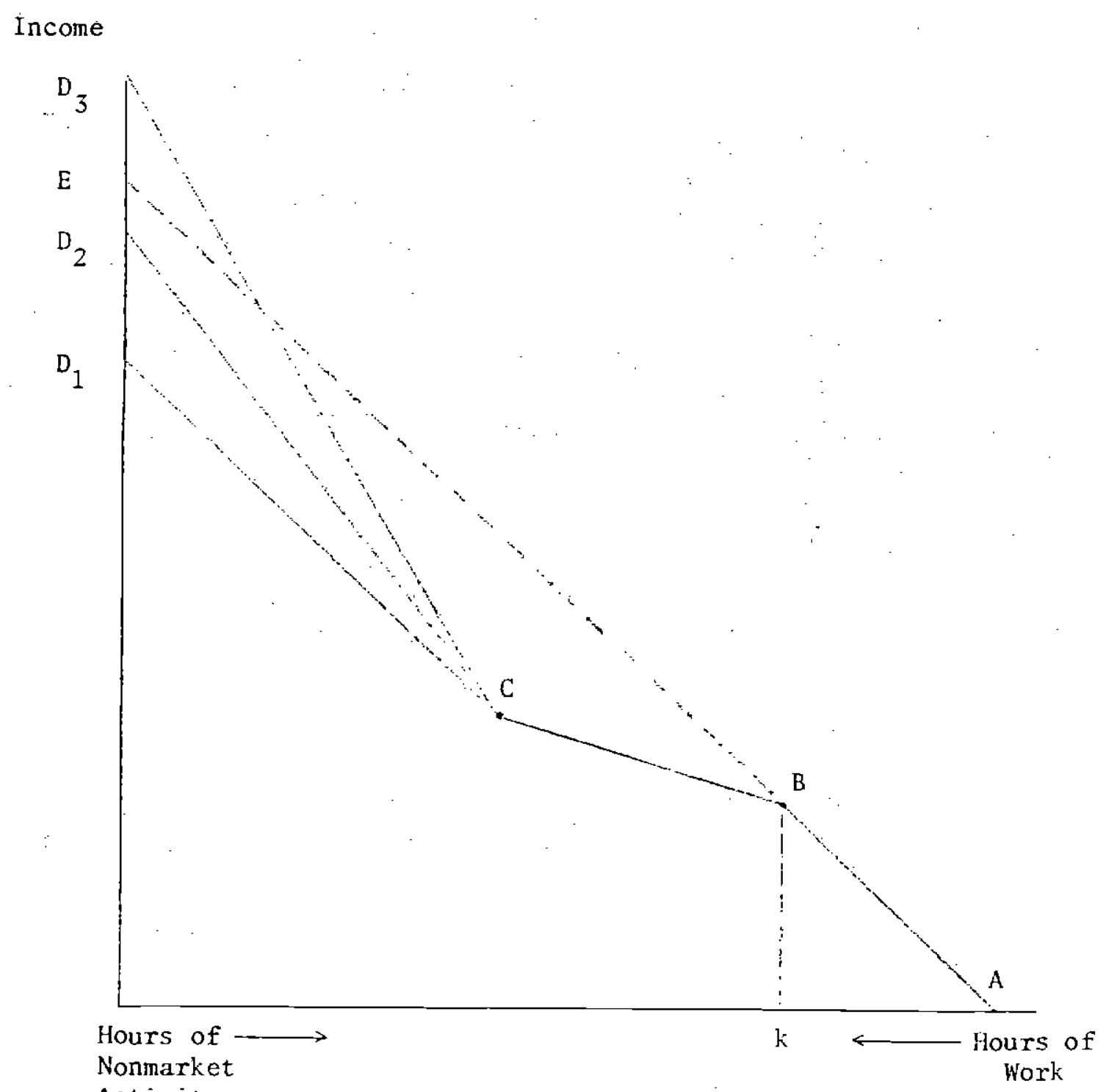


is satisfied by $A B C D_{1}$ and $A B C D_{2}$. Even when the slope of a segment of the budget constraint exceeds the slope of its initial segment, as in the case of $A B C D_{2}$, this condition is still sufficient for the validity of the above methods.

If the above condition is not met, an individual could have his shadow price equal the slope of the budget constraint when it is above the extension of its initial segment and also satisfy the equilibrium condition for working below k. In other words, equilibrium conditions for working above and below $\mathrm{k}$ can be met. This situation is illustrated by the budget constraint $\mathrm{ABCD}_{3}$ in Figure 2 . When such budget constraints preväil, a utility function must be employed for estimating labor supply. As Heckman (1974b) says "the essence of the problem involves utility comparisons between two or more discrete alternatives."

Individuals face kinked nonconvex budget constraints under programs of income maintenance such as welfare assistance, negative income tax plans; and the social security earnings test. The essential idea of these programs is to offer a grant as income support and reduce (tax). it as a person's earnings go up. The nonconvexity arises because an individual's wage is taxed in the range where his earnings reduce the grant (segment (b) in Fig. 2) and then is not taxed when the grant is reduced to zero (segment (c) in Fig. 2). If there is an initial range over which an individual can work without reducing his grant then the methods presented above can probably be applied. The condition for using these methods is likely to hold because the net wage after the grant is reduced to zero is not likely to exceed the slope of the initial segment. The examination of whether this condition holds is important because it determines whether a labor supply

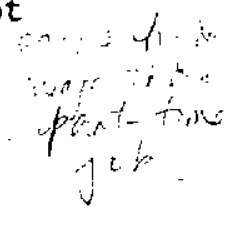
model can be estimated using the methods developed here for which computational procedures already exist or the model requires more complicated analysis. 
This section applied the analysis of discrete choices to estimate the labor supply model. The following sections bring hours of work into the estimation of the model.

\section{Consistent Estimation Using Ordinary Least Squares}

A technique for obtaining consistent estimates of the labor supply model using ordinary least squares is derived in this section. The technique is based on using the distribution of the disturbances in eqs. (1) and (2) for computing the probabilities of working on each segment and corner of the budget constraint. Therefore, the discussion on how choices are made on the kinked convex budget constraint must be taken up again.

The probability that a person works at a level less than k, i.e., along segment (a) in Figure 1 , is given by eqs. (3) and (10) to.be:

$$
P(0<h<k)=P\left(X_{\alpha}-Y_{B}-\gamma k<e_{2}-e_{1}<X_{\alpha}-Y_{B}\right)
$$

Using the same notation from the last section to describe the distribution of $e_{2}-e_{1}$, this probability is expressed as follows:

$$
\mathrm{P}(0<\mathrm{h}<\mathrm{k})=\mathrm{F}\left[\left(\mathrm{X}_{\alpha}-\mathrm{Y}_{\beta}\right) / \sigma\right]-\mathrm{F}\left[\left(\mathrm{X}_{\alpha}-\mathrm{Y}_{\beta}-\gamma \mathrm{k}\right) / \sigma\right]
$$

The wage that a person faces at $k$ is taxed at the rate $t$. A person may be willing to work more than $k$ at his full wage but not at his taxed wage. In 
other words, the market wage can exceed his shadow price at $k$ but his taxed wage does not. For this reason there is a nonzero probability that an individual works $k$ exact $1 y$. Working at 1 east $k$ requires that:

$$
e_{2}-e_{1}<X_{\alpha}-Y \beta-\gamma k
$$

A person works no more than $k$ when $(1-t) w<s$ at $k$. By taking the $10 g$ of this inequality, it is expressed using eqs. (1) and (2) as follows:

$$
e_{2}-e_{1}>\ln (1-t)+X \alpha-Y \beta-\gamma k
$$

Based on eqs. (15) and (16) the probability of working at the corner on the budget constraint where $h=k$ becomes:

$$
P(h=k)+P\left(1 n(1-t)+X \alpha-Y \beta-\gamma k<e_{2}-e_{1}<X_{\alpha}-Y \beta-\gamma k\right)
$$

This probability is further expressed as follows:

$$
P(h=k)+F[(X \alpha-Y \beta-\gamma k) / \sigma]-F[(\ln (1-t)+X \alpha-Y \beta-\gamma k) / \sigma]
$$


A concentration of individuals working $\mathrm{k}$ may appear because some individuals work as much as possible at their full wage but will not work any more at their taxed wage. 12

Finally, a person will work along the taxed segment of the budget constraint when his net wage exceeds his shadow price at $k$ so that:

$$
e_{2}-e_{1}<\ln (1-t)+X_{\alpha}-Y_{\beta}-\gamma h
$$

The probability of working more than $\mathrm{k}$ is given by:

$$
\mathrm{P}(\mathrm{h}>\mathrm{k})=\mathrm{F}[(\ln (1-t)+X \alpha-Y \beta-\gamma \mathrm{k}) / \sigma]
$$

The labor supply choices over the budget constraint illustrated in. Figure 1 and the probabilities of making these choices are summarized in Table 1. The indexes derived in this section to describe these choices are given in the table also.

The technique for consistently estimating the model is based on the probabilities in Table 1 and an equation for the specific amount of labor supplied. Consequently, the focus of attention turns to the labor supply equation that follows from eqs. (1) and (2). This equation is derived by equating shadow price and market wage and solving for $h$. For the moment, the problems posed by the kinked budget constraint are ignored so that this equation is: 
Table 1

LABOR SUPPLY CHOICES AND THEIR PROBABILITIES

Labor Supply Choice

Nonparticipation, $\mathrm{h}=0$

Along segment (a), $0<\mathrm{h}<\mathrm{k}$

At corner, $h=k$

Along segment (b), $h>k$
Probability of Choice*

$1-\mathrm{F}\left(\mathrm{J}_{0}\right)$

$F\left(J_{0}\right)-F\left(J_{k}\right)$

$F\left(J_{k}\right)-F\left(J_{k}^{t}\right)$

$\mathrm{F}\left(\mathrm{J}_{\mathrm{k}}^{\mathrm{t}}\right)$

* The indexes used in the probabilities of choices are:

$$
\begin{aligned}
J_{0}= & (X \alpha-Y \beta) / \sigma, \text { the participation index; } \\
J_{k}= & (X \alpha-Y \beta-\gamma k) / \sigma \text {; the index for working up to } k ; \\
J_{k}^{t}= & \left(\ln (1-t)+X_{\alpha}-Y_{\beta}-\gamma k\right) / \sigma \text {, the index for } \\
& \text { working beyond } k .
\end{aligned}
$$




$$
h=X(\alpha / \gamma)-Y(\beta / \gamma)+\left(e_{2}-e_{1}\right) / \gamma
$$

This equation shows that labor supply is a linear multiple $(1 / \gamma)$ of the difference between market wage and reservation wage. Therefore, this difference determines whether a person works and how much time he spends working. Even without the complication of a kinked budget constraint, the participation and labor supply decisions may not be so strictly related. The coefficients of some of the $X$ and $Y$ variables in the participation step may differ from the corresponding coefficients in the labor supply equation. The point made in the discussion on the fixed cost of children in the last section applies here as well. To allow for this possibility and to simplify the expressions in subsequent calculations, the labor supply equation will be specified in the following general way:

$$
h=W d+u
$$

$W$ is just the set of all variables in $X$ and $Y$; it is doubtful that a variable in either the wage or shadow price equation would not appear in the labor supply equation and vice versa. The difference between eqs. (21) and (22) is in the vector of coefficients. The essential point is that the strict derivation of labor supply from the market wage and shadow price equations can be examined empirically by testing whether the coefficients in eq. (22) are different from those in eq. (21). This point is made by Hunoch (1976, p. 13). To estimate eq. (22) the problems posed by the kinked budget constraint must be handled. 
The technique for consistent estimation of eq. (22) using ols follows from calculating the expected value of $h$ over the kinked budget constraint. To illustrate this, let $q$ index the types of labor supply choices where $q$ equals 1 for not working, 2 for working along segment (a), 3 for working at $k$, and 4 for working along segment (b). The expected value of $h$ conditional on $W$ is:

$$
\left.E(h \mid w)=\sum_{i=1}^{4} p(q=i)\left[w_{q}^{d}\right)+E(u \mid w, q)\right]
$$

where $P(q=i)$ equals the probability of making choice $q=i$; these probabilities are given in Table 1. Estimates of these probabilities follow from the probit analysis of DK presented in Section II.

The $q$ subscript for $W$ indicates that the value of some variables in $W$ depend on the labor supply choice. For example, the value of the tax rate depends on labor supply. The problem posed by this dependency was referred to in the introduction as the tax selection problem. The source of this problem is shown explicitly. in eq. (23): the error term depends on $q$ and hence is potentially correlated with the choice-dependent value of a variable. However, this problem does not arise with the specification given by eq. (23) because the variables are not defined by the value of $q$ that is chosen. Instead, the value of a variable equals the probability weighted average of its values for a11 possible choices.

An important result of the above expected value calculation is that the expected value of the error term equals zcro. This can be shown by writing out the summation in eq. (23) in full. The values of the probability weights, $P(q=i)$, are given in Table 1 . The expected value of $u$ for a given value of 
$q, E(u \mid w, q)]$, is nonzero because $u$ is potentially correlated with $e_{2}-e_{1}$ and $e_{2}-e_{1}$ has been shown to be truncated for any particular choice. Letting oue denote this potential correlation and $f$ denote the standard normal density. function, and using the formulas for the means of truncated normal variables ${ }^{13}$, the expansion of eq. (23) becomes:

$$
\begin{aligned}
E(h \mid W) & =\left[1-F\left(J_{0}\right)\right]\left[w_{1} d-\frac{\sigma_{e}}{\sigma} \frac{-f\left(J_{0}\right)^{\prime}}{1-F\left(J_{0}\right)}\right] \\
& +\left[F\left(J_{0}\right)-F\left(J_{k}\right)\right]\left[w_{2} d-\frac{\sigma_{u e}}{\sigma} \frac{f\left(J_{0}\right)-f\left(J_{k}\right)}{F\left(J_{0}\right)-F\left(J_{k}\right)}\right] \\
& +\left[F\left(J_{k}\right)-F\left(J_{k}^{t}\right)\right]\left[w_{3} d-\frac{\sigma_{e}}{\sigma} \frac{f\left(J_{k}\right)-f\left(J_{k}^{t}\right)}{F\left(J_{k}\right)-F\left(J_{k}^{t}\right)}\right] \\
& +\left[F\left(J_{k}^{t}\right)\right]\left[w_{4}^{d}-\frac{\sigma_{u e}}{\sigma} \frac{f\left(J_{k}^{t}\right)}{F\left(J_{k}^{t}\right)}\right]
\end{aligned}
$$

It follows immediately that:

$$
E(h \mid W)=\left[\sum_{i=1}^{4} p(q=i) W_{q}\right] d
$$

The probability weighted average of the expected value of $u$, as shown, equals zero. There is no selection problem because the actual labor supply choice was not used to calculate the conditioned mean of $h$. Therefore, neither the expected value of the error nor an explanatory variable depend on this choice. 
The only conditioning variables in eq. (24) are the exogenous variables given by $W$. The fact that some variables, in particular the tax rate, differ in value over the budget constraint is handled by taking their expected value over the constraint. In other words, the kinked budget constraint is summarized in an expected value calculation. This suminary of the budget constraint answers Rosen's (1976) request for a way to represent the wole opportunity locus.

An important variable in $W$ is the net wage and the way it is treated in eq. (25) illustrates some important features of the procedure. The coefficient of this variable will be denoted $d_{1}$. For the moment, each individual's market wage, $w$, is assumed to be constant and observed. The net wage varies over the budget constraint because the tax rate changes; for example, in Fig. 1, the tax rate for $q=1$ and 2 is zero and for $q=3$ and 4 it is $t$. In general, let $t_{q}$ be the tax rate that individuals face for choice $q$. Letting $z$ be the variables in $w$ other than the net wage and $d_{z}$ be the vector of their coefficients, eq. (25) becomes:

$$
\begin{aligned}
E(h \mid w)= & d_{1}\left[\sum P(q=i) \ln \left(I-t_{q}\right) w\right]+\left[\sum P(q=i) z_{q}\right] d_{z} \\
= & d_{1}\left[\sum P(q=i) \ln w+d_{1}\left[\sum P(q=i) \ln \left(1-t_{q}\right)\right]\right. \\
& +\left[\sum P(q=i) z_{q}\right] d_{Z} \\
= & d_{1} \ln w+d_{1}\left[\sum P(q=i) \ln (I-t)\right]+\left[\sum P(q=i) z_{q}\right] d_{Z}
\end{aligned}
$$


where $\sum$ expresses summation over $q$.

The first term shows that a variable which is constant over the budget constraint assumes its constant value in the specification given by eq. (25) since the probabilities sum to one. The second term shows that labor supply is a function of all the tax rates as mentioned in the introduction, and eq. (26) offers a convenient way to express this. A further implication is that the coefficients of $\ln w$ and the expected tax rate should be equal. This equality suggests a simple test of tax perception of the type carried out by Rosen (1976).

An important feature of eq. (26) is that it is possible to simulate responses to changes in the tax program based on the specification of the equation. The breakpoints and tax rates of the program are used to define the $J$ indexes and the probability weights follow directly from estimates: of these indexes. Consequently, when the breakpoints or tax rates are changed, the probability weights change which results in a potential change in the expected value of hours of work for each individual as given by eq. (26).

If each individual's wage rate is not observed then there are alternative ways to estimate eq. (25). One way is to substitute the equation for $w$ into eq. (26) so that the $X^{\prime}$ 's appear as explanatory variables with $\mathrm{d}_{1}^{\alpha}$ as the vector of their coefficients. The estimate of eq. (26) based on the X's and the wage regression can be used to estimate $d_{1}$. This procedure is identical to what was done in Section II to estimate $\beta$ based on a probit analysis and the wage regression. Again, Let $x_{1}$ denote a variable in $X$ and not in $Y$. The wage regression $y$ ields an estimate of $x_{1}$ 's coefficient in the wage equation- $\hat{\alpha}_{1}$. The estimate of eq. gives an estimate of $x_{1}$ 's coefficient in the labor supply equation $-\mathrm{d}_{1} \hat{\alpha}_{1}$. An estimate of $d_{1}$ is given by $d_{1} \hat{\alpha}_{1} / \hat{\alpha}_{1}$. Overidentification of $d_{1}$ follows when more than one variable appears in $X$ but not in $Y$. Another way to estimate eq. (26) 
solves this problem of overidentification. The solution is analogous to what was done before: the wage regression is used to impute a $\log$ of wage to everyone based on their $X$ values and the imputed $\log$ of wage is used in eq: (26) as an explanatory variable. The coefficient of the imputed log of wage provides an estimate of $d_{1}$. Again, the equality of the wage and tax coefficient can be tested as a way to test tax perception.

The main result of this section is expressed by eq. (26). Ordinary least squares estimation of the labor supply model based on this specification yields a consistent estimate of the model in the presence of a convex kinked budget constraint. The way in which this specification summarizes the budget constraint in an expected value has a certain intuitive appeal. Although the procedure for implementing this specification requires probit analysis as a first step and the calculation of estimates of the probabilities given in Table 1 from the probit. results, it is not computationally burdensome. More importantly, the steps in the procedure build on themselves and constitute a thorough empirical examination of labor supply. In the process it is possible to test tax perception as well as measure tax effects.

The model is developed to the point where maximum likelihood estimation is easy to discuss. The value of this discussion lies in presenting a way to test the source of information in the estimates of the model.

\section{Maximum Likelihood Estimation}

This section will describe ways to estimate the labor supply model based on likelihood maximization. Most of the derivations and formulas needed to define the likelihood function have been presented in the previous sections. However, the specific amount of labor supplied by individuals who work on a linear 
segment of the budget constraint gives additional information on the probability of their choice, which is put to use here. To be specific, a person who chooses to work an amount $h^{*}$ along segment (a), i.e. $0<h^{*}<k$, is considered. Based on the assumptions that individuals can work any amount they want and that they choose their labor supply so as to equate shadow price and net wage, it follows that:

$$
e_{2}-e_{1}=X_{\alpha}-Y \beta-\gamma h^{*}
$$

Based on this equality and eq. (14) and letting f denote the density function for $e_{2}-e_{1}$, the probability of working along segment (a) at $h$ * becomes:

$$
P(h=h * \mid 0<h<k)=\frac{f\left(X_{\alpha}-Y \beta-\gamma h^{\star}\right)}{F\left(J_{0}\right)-F\left(J_{k}\right)}
$$

This probability and the probability for working along segment (b) will be expressed more conveniently by defining the following $J$ indexes:

$$
\begin{array}{r}
J_{*}=\left(X_{\alpha}-Y \beta-\gamma h^{*}\right) / \sigma \text { for choices along segment (a), } \\
\text { i.e., } 0<h^{*}<k
\end{array}
$$

or,

$$
\begin{aligned}
J_{*}^{t}=\left(\ln (1-t)+X \alpha-Y \beta-\gamma h^{\star}\right) / \sigma, & \text { for choices a long } \\
& \text { segment (b), i.e., } h^{\star}>k .
\end{aligned}
$$


In order to define the likelihood of observing the behavior in a sample, individuals are grouped by the labor supply choice they actually make. Thus, the sample is partitioned as follows: $D_{0}$ for nonworkers; $D_{1}$ for persons working along segment (a); $D_{2}$ for persons working at the kink point; and $D_{3}$ for persons working more than $k$. Given this partition and the probabilities of making. these choices, the likelihood of observing this behavior is given by:

$$
\begin{aligned}
& L=\underset{i \in D_{0}}{\Pi\left[1-F\left(J_{0_{i}}\right)\right]} \cdot \underset{i \in D_{1}}{\prod} f\left(J_{*}\right) /\left[F\left(J_{0}\right)-F\left(J_{i}\right)\right]
\end{aligned}
$$

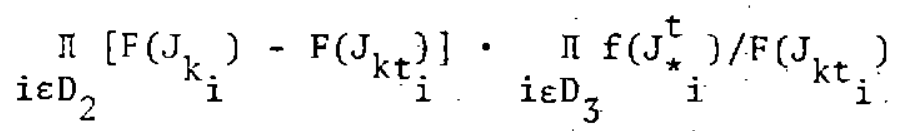

Asympotically efficient, consistent estimates of the coefficients in the model are obtained by maximizing the likelihood function with respect to these coefficients. ${ }^{14}$

The above likelihood function was based, in part, on the assumption that individuals equate shadow price and net wage in determining their labor supply. However, individuals may not be able to choose their hours of work freely because employers offer jobs for specific amounts of work. As a result, work choices along linear segments do not follow from tangencies of indifference curves with budget constraints. By dropping this tangency assumption the likelihood function becomes:

$$
\begin{aligned}
& L=\underset{i \in D_{0}}{\pi}\left[1-F\left(J_{0}\right) \underset{i \in D_{1}}{\pi}\left[F\left(J_{0}\right)-F\left(J_{i}\right)\right]\right. \\
& \prod_{i \in D_{2}}\left[F\left(J_{k_{i}}\right)-F\left(J_{k_{i}}^{t}\right)\right] \underset{i \in D_{3}}{\pi} F\left(J_{i}^{t}\right)
\end{aligned}
$$


This adjustment for dropping the tangency assumption is identical to what Rosett and Nelson (1975) do in the two-limit probit model when nonlimit values of the dependent variable are not known.

The maximization of the likelihood functions given by eqs. (29) and (30) permits testing the source of information in the coefficient estimates. If the value of the likelihood function given by eq. (29) is significantly higher than that based on eq. (30) than additional information is gained by assuming that individuals equate shadow price and net wage. This result would support the usual description of labor supply as an equilibrium that follows from a tangency of an indifference curve with the budget line.

If the maximum likelihood estimates from eqs. (29) and (30) are not significantly different then the assumption that shadow price equals net wage along linear segments of the budget constraint does not add much information empirically. In other words, most of the information for labor supply estimation is captured by the comparison of shadow price and net wage that determines which linear segment or corner of the budget constraint is chosen; variation in labor supply along linear segments does not add much precision to the estimate of the model.

This section presented maximum likelihood methods estimation that followed naturally from the consistent methods developed in the previous section. A test of the source of information in model estimates was also presented. Both the consistent and maximum likelihood methods were given for a convex budget constraint. The problem posed by a nonconvex constraint and the accompanying adjustments to each method are presented in the next section. 
V. Adjustments for the Nonconvex Budget Constraints

The purpose of this section is to point out precisely what problem arises for the estimation procedures given in Sections III and IV when they are applied to a nonconvex kinked budget constraint, and what adjustments have to be made. For maximum likelihood methods the adjustment is one of interpretation; the likelihood function is defined in the same way as before but the predictive power of the estimates is limited. An adjustment in the probability weights used in the consistent procedure is suggested as a practical solution to the nonconvexity problem.

The nonconvexity problem is best illustrated with the budget constraint - shown in Figure 3. This budget constraint describes a program of income support in which individuals receive a grant or benefit that is reduced by $\$ t$ for every dollar of earnings above a certain amount (bc on the vertical axis). The budget constraint becomes nonconvex at point $D$ where the grant is reduced to zero and earnings can no longer be taxed. At this point, where labor supply equals $n$, net wage rises from its taxed value, (1 - t)w, to the market wage rate, $w$. The shadow price at $n$ can exceed the taxed wage implying that labor supply is less than $\mathrm{n}$. At the same time, this shadow price can be less than the market wage implying that labor supply is greater than $n$.

The following indexes are used to express the nonconvexity problem explicitly:

$$
\begin{aligned}
& J_{n}^{t}=\left(\ln (1-t)+X_{\alpha}-Y_{\beta}-\gamma n\right) / \sigma \text {, the index for working up to } n \\
& J_{n}=\left(X_{\alpha}-Y_{\beta}-\gamma_{n}\right) / \sigma, \text { the index for working beyond } n \text {. }
\end{aligned}
$$


Figure 3

THE NONCONVEX KINKED BUDGET CONSTRAINT THAT

FOLLOWS FROM AN INCOME SUPPORT PROGRAM

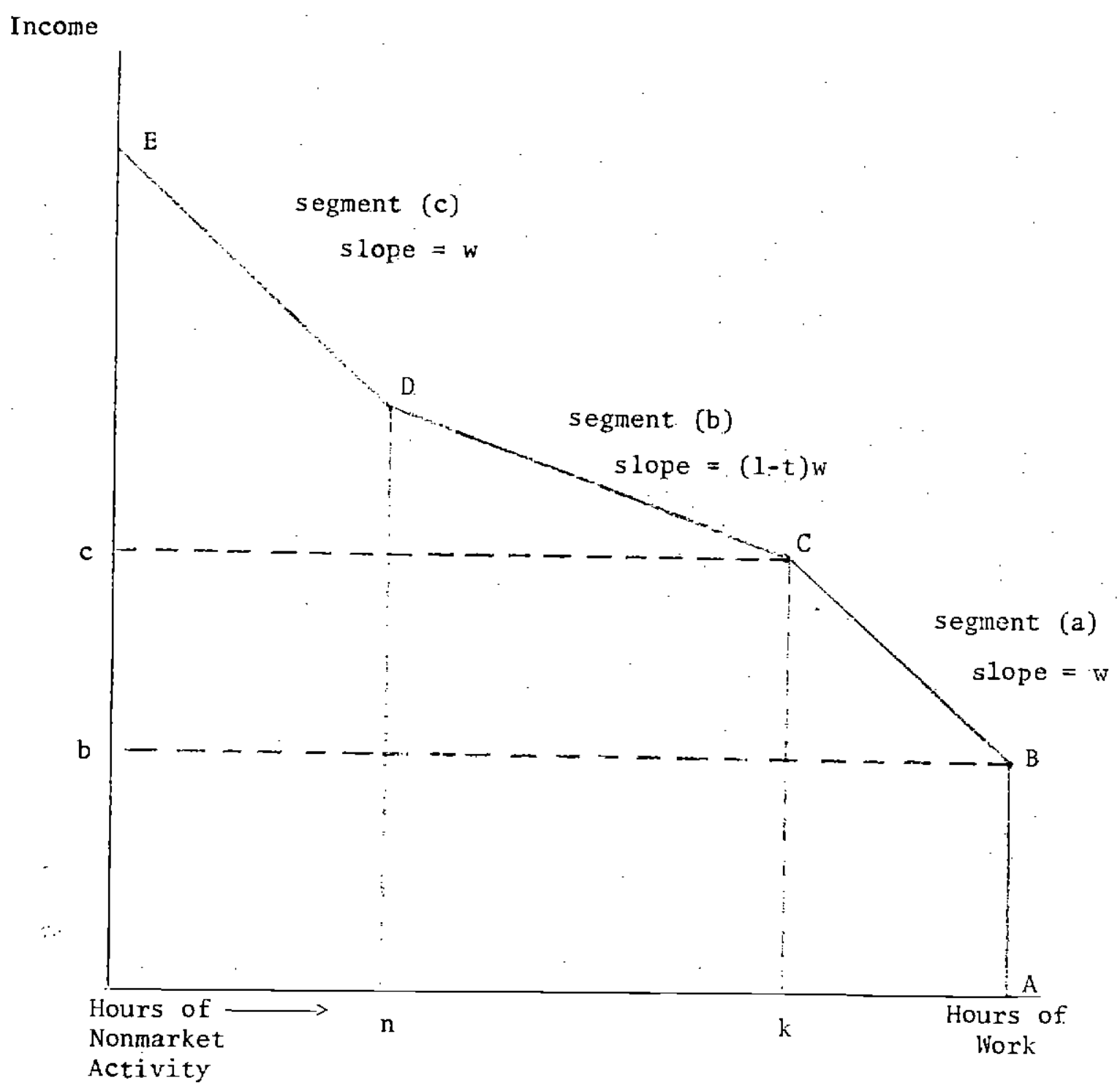


Since $\ln (1-t)<0$, then $J_{n}^{t}<J_{n}$. Therefore, it is possible that $J_{n}^{t}<\left(e_{2}-e_{1}\right)<J_{n}$ where $e_{1}$ and $e_{2}$ are the error terms in the wage and shadow price equations respectively. The first inequality says that the shadow price at $\mathrm{n}$ exceeds the taxed wage and the second inequality, that this shadow price is less than the market wage. Thus, conditions for working below and above $\mathrm{n}$ are both satisfied implying that there are two potential equilibrium points.

One solution to this problem would be to introduce a utility function into the model either by prior specification or through a derivation based on the labor supply equation. With this function, the ambiguity posed by two potential equilịbrium points can be resolved by choosing the one yielding higher utility. This solution is based on the assumption that labor supply is determined by tangencies between indifference curves and budget constraints, i.e., individuals adjust their hours of work freely in order to equate shadow price and net wage. However, individuals may not be able to choose their hours so freely. A utility function based on an assumption that is not supported empirically will not describe labor supply choices accurately.

The tangency assumption is not used in the procedures developed here for estimating labor supply based on probit analysis and likelihood naximization. It is not important for the consistent method because the coefficients in the labor supply equation are allowed to differ from those in the indexes for the probabilities of choices. More importantly, the methodology developed here relies on the data to indicate what steps in the labor supply decision convey the most information for estimation purposes. The methods will be adjusted for the nonconvexity problem in ways that should not cause significant problems empirically. The limitations of these adjustments must be weighted against the potential inaccuracies of a more complicated functional analysis. 
The likelihood function based on the nonconvex budget constraint in Figure 3 would simply add another term to eq. (28) for the subsample of individuals working on segment (c). The probabilities for choosing zero hours, segment (a), and the kink point remain as given in Table 1 . The subgroup of individuals working along segment (b) is again denoted by $\mathrm{D}_{3}$, and the probability of this choice is $F\left(J_{k}^{t}\right)-F\left(J_{n}^{t}\right)$. The subgroup working along segment (c) is denoted by $\mathrm{D}_{4}$, and the probability of this choice is $F\left(J_{n}\right)$. The likelihood function is given as follows:

$$
\begin{aligned}
& L=\prod_{i \in D_{0}}\left[1-F\left(J_{0_{i}}\right)\right] \prod_{i \in D_{0}}\left[F\left(J_{0}\right)-F\left(J_{k_{i}}\right)\right] \\
& \prod_{i \in D_{2}}\left[F\left(J_{k_{i}}\right)-F\left(J_{k i}^{t}\right)\right] \prod_{i \in D_{3}}\left[F\left(J_{k_{i}}^{t}\right)-F\left(J_{n_{i}}^{t}\right)\right] \\
& \prod_{i \in D_{4}} F\left(J_{n_{i}}\right)
\end{aligned}
$$

This function does not take into account the possibility that individuals on segment (b) could have chosen segment (c) and vice versa. Consequently, the model cannot be used to predict jumps between segments (b) and (c) in response to tax changes. This limitation in the predictive power of the model may be less problematic than the restrictions imposed by a utility function.

The probabilities used for the consistent procedure can be adjusted for the problem posed by the nonconvexity. The probability for working at the nonconvexity point, $D$ in Figure 3 where $h=n$, equals $F\left(J_{n}\right)-F\left(J_{n}^{t}\right)$ which is negative. Since a11 the probabiities sum to one, this negative probability at $D$ implies that the sum of the probabilities for the other choices exceeds one by the magnitude of 
this negative amount which is $F\left(J_{n}^{t}\right)-F\left(J_{n}\right)$. This should be interpreted as showing that the comparison of shadow price and net wage gives the expected result that an equilibrium should not occur around the nonconvexity point. The proposed adjustment conforms with this result. The adjustment is to subtract $\left[F\left(J_{n}^{t}\right)-F\left(J_{n}\right)\right] / 2$ from the probabilities for working along segments (b) and (c). As a result, the probability of working in an interval around the nonconvexity point equals zero as expected. 15

In this section, the maximum likelihood and consistent methods were adjusted for the problem posed by a nonconvex budget constraint. The belief is that these adjustments are empirically sourd and are superior to making additional assumptions that may only constrain the data to fit a particular functional form.

VI. Summary and Conclusion

This study develops econometric techniques for estimating labor supply when individuals face a net wage that varies as a result of a program of income maintenance or taxation. The methodology is based on the traditional analysis of labor force participation. Equations for market wage and shadow price are used to describe labor supply choices over a kinked budget constraint. This approach makes a distinction between the discrete choice of which segment or corner of the kinked constraint to work on and the selection of the actual number of hours of work along linear segments. As a result, the methodology can be used to test whether information in an estimate of the model comes from discrete choices or the selection of a specific number of hours. Such an examination of the source of information in model estimates is important because it determines what assumptions about labor supply are appropriate empirically. 
Methods of estimating all the coefficients in the mode1 by the app1ication of probit analysis at certain corners of the budget constraint have been presented. Under a certain condition these methods can be applied to nonconvex constraints.

Comparisons of net wage and shadow price along the budget constraint are used to derive a procedure for consistently estimating the model based on ordinary least squares. An expected value calculation summarizes a variable that changes value over the convex kinked constraint in an intuitively appealing way. Such a variable equals a weighted average of its values on the corners and segments of the constraint. The weights equal the probabilities of choosing to work on each corner and segment. These probabilities vary with the values of the exogenous variables for each individual and with the parameters of the tax program under study. Consequently, an estimate of the model can be used to simulate individual responses to changes in the tax program. An important step in this procedure that precedes the measurement of tax effects is a test of tax perception.

Maximum likelihood estimation of the model follows naturally from consistent procedure. The likelihood approach makes it possible to test the assumption that shadow price and net wage are equal along linear segments of the budget constraint. Adjustments to the maximum likelihood and consistent methods for nonconvex budget constraints were also presented.

There are two points to be made in conclusion that serve as both caveats and defenses for this study. First, individuals may not know exactly. what their budget constraints look like, especially when these constraints are complicated. Consequently, they may make their labor supply decisions based on considering only a few discrete choices as being relevant. 16 Alternatively, they may make their 
decisions based on a subjective expectation of their treatment under a tax system. The methods presented here may go too far because they rely on modelling: the entire budget constraint. However, behavioral responses based on subjective expectations may be suitably captured by the way in which the budget constraint is summarized here in an expected value calculation. A second point is that variables that are crucial for the classification of individual choices over kinked budget constraints e.g. hours and earnings - are subject to errors in measurement. ${ }^{17}$ As a result, this study may assume too much precision in the empirical measurement of the budget constraint. However, the development from probit to consistent to maximum likelihood estimation follows a progression in the use of the budget constraint. How much of the budget constraint is needed for estimation is left to the actual empirical analysis.

I believe this study is useful because it emphasizes an empirical development of a labor supply model. The potential gains from this approach are a realistic description of labor supply decisions, an insight into the amount of information in a dataset, and a robust specification of a labor supply model based on this desription and information. 
Notes

1. Burtless and Hausman (1978) and Hausman (1979) develop a labor supply model in which they use Roy's identity to derive a utility function from a labor supply equation. The problem presented by double tangencies between indifference curves and nonconvex budget constraints is resolved by bringing individual tastes into the model. The coefficient for nonlabor income is assumed to vary with individual tastes. These unobservable tastes are related to observed variables that appear elsewhere in the model. Whenever the same variables are used to serve more than one purpose, misspecification is a serious potential problem. A more fundamental problem is raised in an excellent study by Hall (1975) in which the approach of deriving a utility function from Roy's identity was first taken. Hall shows that empirical results are sensitive to the way in which individual tastes are brought into a labor supply model. This issue of robustness in the specification of individual tastes poses serious questions about Burtless and Hausman's assumption of a random coefficients model applied to one particular coefficient in a model already based on strong assumptions. The motivation of this study is that the empirical development of a labor supply model will yield a robust specification.

2. See Hall (1973); Brown, Levin, and Ulph (1974); Robins and West (1978); Keely, Robins, Spiegelman, and West (1978); and Moffitt (1979).

3. Gronau (1974), Hanoch (1976), Heckman (1974a, b; 1979), and Griliches, Hall, and Hausman (1977).

4. References in addition to those mentioned in n. 3 are Gronau (1973) and Hall $(1973,1975)$.

5. This specification of the wage equation is generally accepted in the labor supply literature; see Heckman and Polachek (1974), Griliches (1977) and Chamberlain (1977). 
6. Hanoch (1976) develops a model in which labor supply is measured by two distinct variables that are jointly determined. Although this description of labor supply has an important bearing on the issues raised here; the main points of this study can be made using a single time dimension.

7. If the wage equation can only be estimated over a sample of workers, then the regression must be corrected for potential sample selection bias. Hanoch (1976) and Heckman (1979) have analyzed this problem and show that potential sample selection bias can be eliminated by adding a variable to the wage regression. This variable is the inverse of Mill's ratio and equals $f\left(J_{0}\right) / F\left(J_{0}\right)$ where $f$ and $F$ are, respectively, the density and distribution functions of $e_{2}-e_{1}$. The probit analysis based on eq. (5) yields an estimate of this variable.

8. Because $\hat{e}_{1}=\left(I-X\left(X^{\prime} X\right)^{-1} X^{\prime}\right) e_{1}$, the validity of the specification in eq. (9) depends on the asymptotic normality of $\hat{\mathrm{e}}_{1}$.

9. There is an important statistical requirement in this two-step procedure. The requirement is that $Y$ be included in the wage regression so that it will be orthogonal to $\mathrm{e}^{\prime}$. Otherwise, the estimate of $\beta$ in the second step is potentially biased.

10. This interpretation is not entirely accurate because the standard deviation $\left(\sigma^{\prime}\right)$ of the error term is not the same as that $(\sigma)$ in the probit analysis based on eq. (5)

11. This example was first discussed by Gronau (1973).

12. An example of such a concentration appears in my study (1979) of the social security earnings test.

13. See Hanoch (1976, P. 15). 
14. A two-step procedure idential to those described above can be used to estimate all the coefficients separately. As before the procedure is based on using an imputed log of wage from the wage regression. Further, the hypothesis that individuals perceive taxes can be tested by testing the equality of the coefficients for the wage and tax variables.

15. A utility function may imply that this interval is slightly different, but this is spurious accuracy given the informational limits of data.

16. Moffit (1979) and Zabalza, Pissarides, Piachaud and Barton (1979) present studies based on two and three choices respectively.

17. Lillard (1978) reports that 6.6 percent of the observed variation in annual earnings and 17.4 percent of the observed variation in annual hours of work are accounted for by measurement error. 


\section{REFERENCES}

Brown, C.V.; E. Levin; and D.T. Ulph.: "On Estimating Labor Supply." University of Stirling, Discussion Paper No. 31, December 1974.

Burtless, Gary and Jerry A. Hausman. "The Effect of Taxation on Labor Supply: Evaluating the Gary Negative Income Tax Experiment." Journal of Political Economy, vol. 86, no: 4, December 1978, pp. 1103-I130.

Chamberlain, Gary. "Education, Income and Ability Revisited." Journal of Econometrics, vol. 5, No.2, 1977, pp. 241-257.

Griliches, Zvi. "Estimating the Returns to Schooling: Some Econometric Problems." Econometrica, vol. 45, no. 1, January 1977, pp. 1-22.

Griliches, Z.; B.H. Hall; and J.A. Hausman. "Missing Data and Self-Selection in Large Panels." Annales de l'INSEE; "The Econometrics of Panel Data." No. 30-31, April-September 1978, pp. 137-176.

Gronau, Reuben. "The Effect of Children on the Housewife's Value of Time: Journal of Political Economy, vol. 81, no. 2, part 2, March/April 1973, pp. S168-S199.

- "Wage Comparisons - A Selectivity Bias." Journal of Political Economy, vol. 82 , no. 6 , November-December 1974 , pp. $1119-43$.

- "Leisure, Home Production, and Work--The Theory of the Allocation of Tíme Revisited." Journal of Political Economy, vol. 85, no. 6, December 1977, pp. 1099-1125.

Ha11, Robert E. "Wages, Income, and Hours of Work in the U.S. Labor Force." In Cain and Watts, eds., Income Maintenance and Labor Supply, Chicago: Markham, 1973, pp. 102-162.

. "Effects of the Experimental Negative Income Tax on Labor Supply." In Pechman and Timpane, eds., Work Incentives and Income Guarantees, Washington D.C.: The Brookings Institution, 1975, pp. 115-147.

Hanoch, Giora. "A Multivariate Model of Labor Supply: Methodology for Estimation." The Rand Corporation, R-1869-HEW, September 1976.

Hanoch, Giora and Marjorie Honig. "The Effect of Social Security Benefits on Labor Supply." The Hebrew University of Jerusalem, Research Report No. 88, May 1976.

Hausman, Jerry A. "The Effect of Wages, Taxes, and Fixed Costs on Women's Labor Force Participation." Massachusetts Institute of Technology, draft; Marcli 1979. 
Heckman, James. "Shadow Prices, Market Wages, and Labor Supply." Econometrica, vol. 42, no. 4, July 1974a, pp. 679-694.

"Effects of Child-Care Programs on Woman'w Work Effort." Journal. of Political Economy, vol. 82, no. 2, part 2, March/April 1974b, $\longrightarrow$ pp. S136-S163.

- "Sample Selection Bias as a Specification Error." Econometrica, vol. 47, no. 1, January 1979, pp. 153-161.

Heckman, James and Solomon Polachek. "Empirical Evidence on the Functional Form of the Earnings - Schooling Relationship." Journal of the American Statistica1 Association, vol: 69, no. 346, June 1974, pp. 350-354.

Keely, Michael C.; Philip K. Robins; Robert G. Spiegelman; and Richard W. West. "The Estimation of Labor Supply Models Using Experimental Data." Anerican Economic Review, vol. 68, no. 5, December 1978, pp. 873-895.

Lillard, Lee A: "Estimation of Permanent and Transitory Response Functions in Panel Data: A Dynamic Labor Supply Model." Annales de l'INSEE, "The Econometrics of Pane1 Data." no. 30-31, April-September 1978, pp. 367-394.

Maddala, G.S. "Identification and Estimation Problems in Limited Dependent Variable Models." University of Florida Working Paper No. 76-77-12, November 1976.

Moffitt, Robert A. "A Note on the Effect of Taxes and Transfers on Labor Supply." Southern Economic Journal, vol. 45, no. 4, April 1979, pp. 1266-1273.

Pellechio, A.J. "The Effect of the Social Security Earnings Test on Labor Supply." National Bureau of Economic Research, draft, August 1979.

Robins, Philip K. and Richard W. West. "Participation in the Seattle and Denver Income Maintenance Experiments and Its Effect on Labor Supply." Center for the Study of Welfare Policy, SRI International, Research Memorandum 53, March 1978.

Rosen, Harvey S. "Taxes in a Labor Supply Model with Joint Wage-Hours Determinants." Econometrica, vol. 44, no. 3, May 1976, pp.485-507.

Rosett, Richard N. and Forrest D. Nelson. "Estimation of the Two-Limit Probit Regression Model." Econometrica, vol. 43, no. 1, January 1975, pp. 141-146.

Zabalza, A.; C. Pissarides; D. Pialchaud; and M. Barton. "Social Security and the Choice Between Full-time Work, Part-time work and Retirement." London School of Economics, draft, 1979. 